1

2

3

4

5

6

7

8

9

10

11

12

13

14

15

16

17

18

19

20

21

22

23

24

25

26

27

28

29

\title{
Hypothesis
}

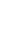

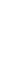

(

\section{Cetacean morbillivirus, a journey from land to sea and viceversa}

(1)

(1)

Giovanni Di Guardo ${ }^{1 *}$ and Sandro Mazzariol²

(1) 12

${ }^{1}$ University of Teramo, Faculty of Veterinary Medicine, Località Piano d'Accio, 64100 - Teramo, Italy;

${ }^{2}$ University of Padua, Department of Comparative Biomedicine and Food Science, Agripolis, 35020 Legnaro (Padova), Italy;

*Correspondence: Giovanni Di Guardo,gdiguardo@unite.it

17

18

9

0

1

7 Keywords: Cetacean Morbillivirus; Canine Distemper Virus; Rinderpest Virus; Viral phylogeny; Viral evolution; Host-pathogen interactions; Cetaceans; Aquatic Mammals. 29 
$31 \quad$ Abstract

Cetacean Morbillivirus, the most relevant pathogen impacting the health and conservation of cetaceans worldwide, has shown in recent years an increased tendency to cross "interspecies barriers", thereby giving rise to disease and mortality outbreaks in free-ranging dolphins and whales. The present article deals with the evolutionary "trajectories" of this viral pathogen, likely originating from Rinderpest Virus, along with its "journey" from land to sea (and viceversa), mimicking that of cetaceans' terrestrial ancestors.

Cetacean Morbillivirus (CeMV), the most relevant pathogen impacting the health and conservation of several already threatened cetacean populations worldwide [1], has shown in recent years an increased tendency to cross "interspecies barriers" [2], thereby giving rise to disease and mortality outbreaks in free-ranging dolphins and whales [3-5]. Additional cases of infection have been also reported in aquatic mammals with a mixed aquatic-terrestrial ecology like common seals (Phoca vitulina) [6] and Eurasian otters (Lutra lutra) [7], with such findings increasing the overall concern and attention towards this Morbillivirus genus member. In this respect, the demonstrated ability of all the 5 hitherto chacterized CeMV strains to utilize indifferently dolphin, dog and seal SLAM/CD150 as host cell receptors [3] provides relevant biological plausibility and support to the aforementioned cross-species viral transmission events. Regarding its progressively expanding host spectrum range, CeMV shares similarities with Canine Distemper Virus (CDV), another global and multi-host morbilliviral pathogen responsible for numerous disease outbreaks in various terrestrial and aquatic wild mammal populations, including Lake Bajkal (Pusa siberica) and Caspian seals ( $P$. caspica) [2, 8], which are known to be susceptible also to Phocine Distemper Virus (PDV) [9]. 
Based upon Bayesian phylogeographic analysis, CeMV has been estimated to be characterized by a mutational rate of $2.34 \times 10^{-4}$ nucleotide substitutions/site/year, with viral evolutionary dynamics turning out to be neither host- nor location-restricted [3].

In this respect, it should be additionally highlighted that Rinderpest Virus (RPV), or a closely related ancestor of cattle origin, is believed to have crossed the "bovine-human transmission barrier" 1,0005,000 thousands years ago, thereby giving rise to Measles Virus, the pathogen most closely related to RPV within the Morbillivirus genus [10]. The origins of rinderpest date back to over 10,000 years ago, coincident with cattle domestication in Asia [10], while the impact of RPV on cattle and on the human populations depending upon bovine productions has been so devastating throughout the centuries that rinderpest was the main motivation for establishing the first Veterinary School in Lyon, France, in 1761 [11]. In 2011, exactly 250 years later, the disease was declared to be globally eradicated, thanks to the use of an efficient anti-RPV vaccine [10, 11].

Due to the common terrestrial ancestor shared between cetaceans and ruminants [12], it could be speculated that the "land to sea transition" characterizing cetaceans' evolutionary phylogeny was probably followed also by CeMV, a marine virus most likely derived from RPV, a terrestrial pathogen $[13,14]$.

In this respect, while a CeMV isolate from the Southern Hemisphere that was identified almost simultaneously in Guyana dolphins (Sotalia guianensis) along the Atlantic coast of Brazil as well as in Indo-Pacific bottlenose dolphins (Tursiops aduncus) from Western Australia [15-17] appears to be the one most closely related to RPV among the 5 hitherto defined CeMV strains [3], it should be once again recalled that fatal cases of infection caused by Dolphin Morbillivirus (DMV, a CeMV strain) have been recently reported in Italy among Eurasian otters, an endangered wild mammal species with a mixed water-terrestrial ecology [7]. Furthermore, starting from 2011, DMV has shown a considerable expansion of its host range in the Western Mediterranean Sea, with lethal episodes of infection having been reported in fin whales as well as among mass-stranded sperm whales $[4,5,18]$, 
while deadly cases of DMV infection have also been described in a Cuvier's beaked whale (Ziphius cavirostris) individual [19] and, surprisingly, even in a captive harbour seal [6].

Should this journey back from sea to land, putatively made by CeMV, worry us? And what implications, if any, could it exert on the feared RPV resurgence in cattle? In this respect, is there a concrete risk that rinderpest, the second infectious disease to be eradicated on Earth after smallpox [11], could re-emerge in cattle and should we pay attention, in such an undesirable scenario, to CeMV and its evolutionary dynamics?

Our answers to the above questions, based upon the so-called "principle of precaution", are affirmative.

As a matter of fact, a zoonotic potential has been recently documented for Peste des Petits Ruminants Virus (PPRV), another morbilliviral agent closely related to RPV, following a single amino acid change within its hemagglutinin (H) antigen [20]. Still notably, also CDV has been shown to successfully infect primate species phylogenetically close to humans, with reports of viral transmission to non-human primates under both natural and experimental conditions, together with a proven CDV adaptation to SLAM/CD150-expressing human cells following a single amino acid substitution in the viral $\mathrm{H}$ protein [21-23].

Finally and not less remarkably, it is our strong belief that adequate consideration should be also given to environmental radiocontamination as an additional factor potantially driving CeMV and, more in general, Morbillivirus and viral genetic make-up mutation(s). To the best of our knowledge, in fact, environmental radiocontamination has not received any attention within such complex and intriguing context. Nevertheless, it should be additionally underscored that, following the dramatic nuclear accident of April 1986 in Chernobyl, Ukraine, three major and entirely unprecedented morbilliviral disease epidemics took place in different aquatic mammal populations from European and neighbouring waters, namely among Lake Bajkal and North Sea common seals [9] as well as among Mediterranean striped dolphins (Stenella coeruleoalba) [1]. The three aforementioned 
104 outbreaks were respectively caused by CDV and by two newly discovered morbilliviruses, PDV and 105 DMV $[1,9]$.

106 As a concluding remark, we believe that further work is absolutely needed in order to better 107 characterize the transmission barrier(s) between CeMV and different cetacean, aquatic mammal and 108 terrestrial hosts, along with the virus- and the host-related factors underlying cross-species jumping 109 within aquatic and terrestrial environments as well as at the level of the various water-land ecological 110 interfaces. 
References

1. Van Bressem MF, Duignan PJ, Banyard A, Barbieri M, Colegrove KM et al. Cetacean morbillivirus: Current knowledge and future directions. Viruses 2014;6:5145-5181.

2. Jo WK, Osterhaus AD, Ludlow M. Transmission of morbilliviruses within and among marine mammal species. Curr Opin Virol 2018;28:133-141.

3. Jo KW, Kruppa J, Habierski A, van de Bildt M, Mazzariol S et al. Evolutionary evidence for multihost transmission of Cetacean morbillivirus. Emerg Microbes Infect 2018; 7:201.

4. Mazzariol S, Centelleghe C, Beffagna G, Povinelli M, Terracciano G et al. Mediterranean fin whales (Balaenoptera physalus) threatened by Dolphin morbillivirus. Emerg Infect Dis 2016;22:302305.

5. Mazzariol S, Centelleghe C, Di Provvido A, Di Renzo L, Cardeti G, et al. Dolphin morbillivirus associated with a mass stranding of sperm whales, Italy. Emerg Infect Dis 2017;23:144-146.

6. Mazzariol S, Peletto S, Mondin A, Centelleghe C, Di Guardo G et al. Dolphin morbillivirus infection in a captive harbor seal (Phoca vitulina). J Clin Microbiol 2013;51:708-711.

7. Padalino I, Di Guardo G, Carbone A, Troiano P, Parisi A, et al. Dolphin morbillivirus in Eurasian otters, Italy. Emerg Infect Dis 2019;25:372-374.

8. Loots AK, Mitchell E, Dalton DL, Kotzé A, Venter EH. Advances in canine distemper virus pathogenesis research: A wildlife perspective. J Gen Virol 2017;98:311-321.

9. Duignan PJ Van Bressem MF, Baker JD, Barbieri M, Colegrove KM et al. Phocine distemper virus: Current knowledge and future directions. Viruses 2014;6:5093-5134.

10. de Vries RD, Duprex WP, de Swart RL. Morbillivirus infections: An introduction. Viruses 2015;7: 699-706.

11. Tounkara K, Nwankpa N. Rinderpest experience. Rev Sci Tech 2017;36:569-578.

12. Thewissen JGM, Cooper LN, George JC, Bajpai S. From land to water: The origin of whales, dolphins, and porpoises. Evo Edu Outreach 2009;2:272-288.

13. Shen T, Xu S, Wang X, Yu W, Zhou Ket al. Adaptive evolution and functional constraint at TLR4 during the secondary aquatic adaptation and diversification of cetaceans. BMC Evol Biol 2012;12:39. 
155 156 157 158 159 160 161 162 163 164 165 166 167 168 169 170 171 172 173 174 175 176 177

14. Ishengoma E, Agaba M. Evolution of toll-like receptors in the context of terrestrial ungulates and cetaceans diversification. BMC Evol Biol 2017;17:54.

15. Groch KR, Colosio AC, Marcondes MC, Zucca D, Díaz-Delgado J et al. Novel cetacean morbillivirus in Guiana dolphin, Brazil. Emerg Infect Dis 2014;20:511-513.

16. Groch KR, Santos-Neto EB, Díaz-Delgado J, Ikeda JMP, Carvalho RR et al. Guiana dolphin unusual mortality event and link to Cetacean morbillivirus, Brazil. Emerg Infect Dis 2018;24:13491354.

17. Stephens N, Duignan PJ, Wang J, Bingham J, Finn H, et al. Cetacean morbillivirus in coastal IndoPacific bottlenose dolphins, Western Australia. Emerg Infect Dis 2014;20:666-670.

18. Mazzariol S, Centelleghe C, Cozzi B, Povinelli M, Marcer F et al. Multidisciplinary studies on a sick-leader syndrome-associated mass stranding of sperm whales (Physeter macrocephalus) along the Adriatic coast of Italy. Sci Rep 2018;8:11577.

19. Centelleghe C, Beffagna G, Palmisano G, Franzo G, Casalone C, et al. Dolphin morbillivirus in a Cuvier's beaked whale (Ziphius cavirostris), Italy. Front Microbiol 2017;8:111.

20. Abdullah N, Kelly JT, Graham SC, Birch J, Gonçalves-Carneiro D et al. Structure-guided identification of a nonhuman morbillivirus with zoonotic potential. $J$ Virol 2018;92 pii:e01248-18.

21. Sakai K, Nagata N, Ami Y, Seki F, Suzaki Y et al. Lethal canine distemper virus outbreak in cynomolgus monkeys in Japan in 2008. J Virol 2013;87:1105-1114.

22. Qiu W, Zheng Y, Zhang S, Fan Q, Liu H, Zhang F et al. Canine distemper outbreak in rhesus monkeys, China. Emerg Infect Dis 2011;17:1541-1543.

23. Sakai K, Yoshikawa T, Seki F, Fukushi S, Tahara M et al. Canine distemper virus associated with a lethal outbreak in monkeys can readily adapt to use human receptors. $J$ Virol 2013;87:7170-7175. 